\title{
The Demographic Characteristics and the Risk Factors of Dementia in SAUDI Elderly
}

\author{
Muneerah Albugami ${ }^{1}$, , Najeeb Qadi ${ }^{2}$, Fahed Almugbel ${ }^{1}$, Alaa Mohammed ${ }^{1}$, Alawi Alttas ${ }^{2}$, \\ Abdelazeim Elamin ${ }^{1}$, Mumin Siddiquee ${ }^{1}$, Usama El Alem ${ }^{1}$, Yasmin Al Twaijri ${ }^{3}$ \\ ${ }^{1}$ Medicine Department, King Faisal Specialist Hospital and Research Centre, Riyadh, Saudi Arabia \\ ${ }^{2}$ Neuroscience Department, King Faisal Specialist Hospital and Research Centre, Riyadh, Saudi Arabia \\ ${ }^{3}$ Department of Biostatistics, Epidemiology and Scientific Computing, King Faisal Specialist Hospital and Research Centre, Riyadh, Saudi \\ Arabia
}

\section{Email address:}

Drmb99@yahoo.com (M. Albugami),nqadi@kfshrc.edu.sa (N. Qadi), fahd2525@hotmail.com (F. Almugbel), dr.alaibrahim@gmail.com (A. Mohammed), alawiattas@yahoo.com (A. Alttas), abdelazeim@hotmail.com (A. Elamin), msiddiquee@kfshrc.edu.sa (M. Siddiquee), uelalem82@kfshrc.edu.sa (U. El Alem), yasmin@kfshrc.edu.sa (Y. Al Twaijri) ${ }^{*}$ Corresponding author

\section{To cite this article:}

Muneerah Albugami, Najeeb Qadi, Almugbel, Alaa Mohammed, Alawi Alttas, Abdelazeim Elamin, Mumin Siddiquee, Usama El Alem, Yasmin Al Twaijri. The Demographic Characteristics and the Risk Factors of Dementia in SAUDI Elderly. American Journal of Psychiatry and Neuroscience. Vol. 6, No. 1, 2018, pp. 1-8. doi: 10.11648/j.ajpn.20180601.11

Received: November 30, 2017; Accepted: December 8, 2017; Published: January 10, 2018

\begin{abstract}
There is a little information about dementia in Saudis. This is a retrospective chart review study from1995 -2010. to describe the demographic characteristics and the risk factors of dementia, the prevalence of different types of dementia, and the current clinical practice of dementia in Saudi tertiary care hospital. A total of 418 demented patients (236 males, 182 females) their mean age was 78.8. Prevalence of diabetes $32 \%$, hypertension $71.53 \%$, dyslipidemia $30.05 \%$ and depression $24.41 \%$. Clinically $64.37 \%$ of patients had memory impairment, $54.25 \%$ had confusion and $34.63 \%$ had personality changing. The commonest type of dementia was mixed dementia 18.37\% followed by Alzheimer disease $15.87 \% .16 .10 \%$ of patients had received cholinesterase inhibitor and $9.78 \%$ had received memantine. Infection was the commonest cause of frequent admission (40\%) Mortality rate was $77.99 \%$. The commonest cause of death was infection (38.34\%) followed by cardiovascular causes like stroke (23.34\%) and cardiac diseases (17.48\%). Conclusion: (1) Mixed dementia is the commonest type of dementia in Saudis due to high prevalence of cardiovascular diseases risk factors. (2) High prevalence of depression among demented Saudi patients. It requires early recognition and treatment. (3) Demented patients have frequent admissions and long stay in hospital which makes the economic cost is very high. (4) Mortality rate among demented patients is high and the outcome of dementia is expected to be poor. The underlying message of this study is to increase awareness of the public and health system about the impact of dementia in Saudis and the need for prevention strategies, trained physicians and more research.
\end{abstract}

Keywords: Dementia, Elderly, Alzheimer's Disease, Mixed Dementia, Depression

\section{Introduction}

Dementia is characterized by the impairment of memory and learning and at least one other cognitive domain (i.e., aphasia, apraxia, agnosia or executive function), representing a highly severe functional deterioration that interferes with the patient's daily functional abilities and independence [1].

Dementia is a syndrome caused by different etiologies and it has a substantial medical and social impact [2]. Dementia prevalence has increased continuously over the past decades due to aging populations. The World Health Organization (WHO) estimated that the number of persons living with dementia worldwide (36 million in 2010) will double over the next 20 years [3].

Saudi Arabia is facing the challenge of an ageing population. According to the last Saudi census in 2011 the 
life expectancy at birth is 74 . Increased in elderly population will have an impact on health care and social services. There is a little information about dementia in Saudis [4]. We have scanty data regarding the demographics characterizing this population or the etiologic diagnoses among those affected in Saudi Arabia.

The objective of this study is to describe the demographic characteristics and the risk factors of dementia, the prevalence of different types of dementia, and the current clinical practice of dementia in Saudi Arabia at tertiary care hospital.

\section{Methods}

It is a retrospective, cohort study utilized chart review of patients have dementia who received regular care at King Faisal Specialist Hospital and Research Centre (KFSH\&RC) in Saudi Arabia from 1995 -2010. Exclusion criteria include depression without dementia and delirium due to acute illness or medications.

\section{Statistical Analysis}

For this study, all the statistical analysis of data was done by using the software package SAS version 9.4 (SAS
Institute Inc., Cary, NC, USA). Descriptive statistics for the continuous variables are reported as mean \pm standard deviation and categorical variables are summarized as frequencies and percentages. The categorical variables are compared by Chi-square test. The level of statistical significance is set at $\mathrm{p}<0.05$.

\section{Results}

A total of 418 demented patients (236 males, 182 females). The mean age was 78.8 and $63.41 \%$ of patients diagnosed to have dementia at age $>65$. Their basic characteristics and clinical presentation are shown in table $1 \& 2$.

261 patients $(59.32 \%)$ had diabetes, 314 patients $(71.53 \%)$ had hypertension, 131 patient $(30.05 \%)$ had dyslipidemia, 104 patients $(24.41 \%)$ had depression, 90 patients $(30.72 \%)$ were on medication for depression, 81 patients $(18.93 \%)$ had seizure, 280 patients $(64.37 \%)$ had memory impairment, 236 patient $(54.25 \%)$ had confusion, 151 patients $(34.63 \%)$ had personality changing. Laboratory and radiological investigations are shown in table 3. Neurologists had evaluated 277 patients, internists had evaluated 220 patients, and both had evaluated 130 patients, psychiatrists had evaluated 91 patients.

Table 1. Basic characteristics of dementia patients.

\begin{tabular}{|c|c|c|c|}
\hline Total no. $=418$ & Frequency & Percent (\%) & Mean \\
\hline Current age & & & 78.8 \\
\hline Age on diagnosis $<65$ y & 92 & 22.44 & \\
\hline Age on diagnosis $>65 y$ & 260 & 63.41 & \\
\hline not recorded/missing & 66 & 14.15 & \\
\hline Body mass index on presentation (BMI) & & & 26.4 \\
\hline BMI 7 years after dementia diagnosis & & & 25.5 \\
\hline \multicolumn{4}{|l|}{ Sex } \\
\hline Male & 236 & 56.46 & \\
\hline Female & 182 & 43.54 & \\
\hline \multicolumn{4}{|l|}{ Education level } \\
\hline Collage & 14 & 3.18 & \\
\hline Elementary school & 7 & 1.58 & \\
\hline High school & 1 & 0.23 & \\
\hline Illiterate & 26 & 5.91 & \\
\hline Not recorded/missing & 370 & 89.1 & \\
\hline \multicolumn{4}{|l|}{ Marital status: } \\
\hline -Divorced & 9 & 2.01 & \\
\hline -Married & 232 & 52.73 & \\
\hline -single & 20 & 4.55 & \\
\hline -Widow & 57 & 7.98 & \\
\hline -Not recorded/missing & 100 & 32.73 & \\
\hline \multicolumn{4}{|l|}{ Comorbid conditions } \\
\hline Diabetes mellitus & 261 & 59.32 & \\
\hline Hypertension & 314 & 71.53 & \\
\hline Dyslipidemia & 131 & 30.05 & \\
\hline Seizure & 81 & 18.93 & \\
\hline Depression & 104 & 24.41 & \\
\hline patients on medication for depression & 90 & 30.72 & \\
\hline \multicolumn{4}{|l|}{ Cigarette smoking } \\
\hline Yes & 22 & 5.02 & \\
\hline No & 110 & 25.11 & \\
\hline Not recorded/missing & 286 & 69.87 & \\
\hline \multicolumn{4}{|l|}{ Alcohol } \\
\hline Yes & 3 & 0.68 & \\
\hline No & 103 & 23.41 & \\
\hline
\end{tabular}




\begin{tabular}{lll}
\hline Total no. $=\mathbf{4 1 8}$ & Frequency & Percent (\%) \\
\hline Not recorded/missing & 312 & 75.91 \\
Family history of dementia & & \\
Yes & 8 & 1.82 \\
No & 97 & 22.04 \\
Not recorded/missing & 313 & 76.14 \\
Stroke & 46 & 15.03 \\
Parkinson disease & 17 & 5.55 \\
Chronic kidney disease & 113 & 36.93 \\
Hypothyroidism & 12 & 3.92 \\
HIV & 8 & 2.61 \\
Brain Malignancy & 10 & 3.27 \\
Ischemic heart disease & 16 & 5.23 \\
Atrial fiblation & 8 & 2.61 \\
Hepatitis B virus & 1 & 0.33 \\
Hepatitis C virus & 3 & 0.98 \\
Liver cirrhosis & 3 & 0.98 \\
Tuberculosis & 3 & 0.98 \\
Normal pressure hydrocephalus have shunt & 4 & 1.31 \\
Multiple sclerosis & 2 & 0.65 \\
Neurosyphilis & 1 & 0.33 \\
Vasculitis & 2 & 0.65 \\
More than 3Comorbid condition & 121 & 27.44 \\
Feeding & & \\
Oral feeding & 93 & 21.14 \\
Nasogastric tube (NGT) & 37 & 8.41 \\
Gastrostomy tube (GT) & 134 & 30.45 \\
Jejunostomy tube (JGT) & 6 & 1.36 \\
Not recorded/missing & 148 & 38.64 \\
\hline
\end{tabular}

Table 2. Clinical presentation.

\begin{tabular}{lll}
\hline Clinical presentation & Frequency & Percent (\%) \\
\hline Memory impairment & 280 & 64.37 \\
Confusion & 236 & 54.25 \\
Personality change & 151 & 34.63 \\
Visual hallucination & 9 & 12.5 \\
Agitation & 8 & 11.11 \\
Urine incontinence & 6 & 1.96 \\
Poor oral intake & 1 & 1.39 \\
More than 3 symptoms & 122 & 27.66 \\
\hline
\end{tabular}

Table 3. Laboratory and radiological investigations.

\begin{tabular}{|c|c|c|c|c|c|}
\hline Laboratory Investigations Results & Frequency & Percent (\%) & Radiological Investigation & Frequency & Percent (\%) \\
\hline Vitamin B12 & & & CT brain & & \\
\hline Low & 11 & 2.63 & Normal & 23 & 5.11 \\
\hline Normal & 126 & 30.14 & Atrophy & 129 & 28.67 \\
\hline High & 76 & 18.19 & Vascular changes & 163 & 36.22 \\
\hline \multirow[t]{3}{*}{ not recorded/missing } & 205 & 49.04 & Evidence of stroke & & \\
\hline & & & White matter changes & 119 & 26.44 \\
\hline & & & & 16 & 3.56 \\
\hline Folate & & & MRI brain & & \\
\hline Low & 3 & 0.72 & Normal & 4 & 0.85 \\
\hline Normal & 86 & 20.57 & Atrophy & 62 & 13.20 \\
\hline High & 74 & 17.70 & Vascular changes & 61 & 12.98 \\
\hline not recorded/missing & 255 & 61 & Evidence of stroke & 130 & 27.66 \\
\hline & & & White matter changes & 213 & 45.31 \\
\hline Thyroid stimulating hormone (TSH) & & & Doppler carotid US & & \\
\hline Low & 14 & 3.35 & Normal & 35 & 8.38 \\
\hline Normal & 246 & 58.85 & & & \\
\hline High & 55 & 13.16 & Stenosis & 21 & 5.02 \\
\hline Not done & 15 & 3.59 & & 362 & 86.60 \\
\hline not recorded/missing & 88 & 21.05 & not recorded/missing & & \\
\hline Syphilis & & & EEG & & \\
\hline Negative & 84 & 20.11 & Abnormal & 70 & 16.76 \\
\hline Positive & 12 & 2.88 & Normal & 12 & 2.87 \\
\hline not recorded/missing & 322 & 77.01 & not recorded/missing & 336 & 80.37 \\
\hline
\end{tabular}




\begin{tabular}{|c|c|c|c|c|c|}
\hline Laboratory Investigations Results & Frequency & Percent (\%) & Radiological Investigation & Frequency & Percent (\%) \\
\hline HIV & & & CSF analysis & & \\
\hline Negative & 76 & 18.2 & Abnormal & 16 & 3.83 \\
\hline Positive & 8 & 1.9 & Normal & 48 & 11.48 \\
\hline \multirow[t]{2}{*}{ not recorded/missing } & 334 & 79.9 & Not done & 325 & 77.75 \\
\hline & & & not recorded/missing & 29 & 6.94 \\
\hline \multicolumn{6}{|l|}{ Creatinine level } \\
\hline Low & 10 & 2.39 & & & \\
\hline Normal & 290 & 69.38 & & & \\
\hline High & 113 & 27.03 & & & \\
\hline not recorded/missing & 5 & 1.20 & & & \\
\hline \multicolumn{6}{|l|}{ ALT level in hepatic profile } \\
\hline Low & 8 & 1.91 & & & \\
\hline Normal & 375 & 89.71 & & & \\
\hline High & 30 & 7.18 & & & \\
\hline not recorded/missing & 5 & 1.20 & & & \\
\hline \multicolumn{6}{|l|}{ Hemoglobin } \\
\hline Low & 147 & 35.17 & & & \\
\hline Normal & 213 & 50.96 & & & \\
\hline High & 9 & 2.15 & & & \\
\hline not recorded/missing & 49 & 11.72 & & & \\
\hline \multicolumn{6}{|l|}{ WBC } \\
\hline Low & 7 & 1.67 & & & \\
\hline Normal & 359 & 85.89 & & & \\
\hline High & 50 & 11.96 & & & \\
\hline not recorded/missing & 2 & 0.48 & & & \\
\hline \multicolumn{6}{|l|}{ Platelet } \\
\hline Low & 22 & 5.3 & & & \\
\hline Normal & 361 & 86.4 & & & \\
\hline High & 28 & 6.7 & & & \\
\hline not recorded/missing & 7 & 1.6 & & & \\
\hline \multicolumn{6}{|l|}{ Total cholesterol } \\
\hline Low & 4 & 0.96 & & & \\
\hline Normal & 177 & 42.34 & & & \\
\hline High & 134 & 32.06 & & & \\
\hline not recorded/missing & 103 & 24.64 & & & \\
\hline \multicolumn{6}{|l|}{ LDL } \\
\hline Low & 2 & 0.48 & & & \\
\hline Normal & 179 & 42.82 & & & \\
\hline High & 233 & 55.74 & & & \\
\hline not recorded/missing & 4 & 0.96 & & & \\
\hline \multicolumn{6}{|l|}{ Triglyceride } \\
\hline Low & 1 & 0.24 & & & \\
\hline Normal & 199 & 47.61 & & & \\
\hline High & 35 & 8.37 & & & \\
\hline not recorded/missing & 183 & 43.78 & & & \\
\hline \multicolumn{6}{|l|}{ HDL } \\
\hline Low & 17 & 4.06 & & & \\
\hline Normal & 205 & 49.04 & & & \\
\hline High & 4 & 0.96 & & & \\
\hline not recorded/missing & 192 & 45.94 & & & \\
\hline \multicolumn{6}{|l|}{ HBA1C } \\
\hline Normal & 116 & 27.75 & & & \\
\hline High & 202 & 48.33 & & & \\
\hline not recorded/missing & 100 & 23.92 & & & \\
\hline \multicolumn{6}{|l|}{ Anti DNA profile } \\
\hline Normal & 155 & 37.08 & & & \\
\hline High & 17 & 4.07 & & & \\
\hline not recorded/missing & 246 & 58.85 & & & \\
\hline
\end{tabular}

81 patients $(18.37 \%)$ had mixed dementia, 70 patients (15.87\%) had Alzheimer disease, 34 patients (7.71\%) had vascular dementia, 17 patients $(3.85 \%)$ had Parkinson dementia, 10 patients $(2.27 \%)$ had Lewis body dementia, 6 patients $(1.36 \%)$ had frontotemporal dementia, only 110 patients $(25.88 \%)$ had received treatment of dementia, 71 patients $(16.10 \%)$ had received cholinesterase inhibitor, 39 patients $(9.78 \%)$ had received memantine, $21.14 \%$ patients on oral feeding, $8.41 \%$ on nasogastric tube (NGT), $30.45 \%$ on gastrostomy tube (GT) \& $1.36 \%$ on jejunostomy tube (JGT). $40 \%$ of the causes of frequent admission to hospital were infection like aspiration pneumonia $(27 \%)$, urinary tract infection $(10.24 \%)$, bed sores infection $(2.76 \%)$, followed by cardiac causes $(24.52 \%)$ like heart failure $11.06 \%$, ischemic 
heart diseases $13.46 \%$, family members had taken care of 210 patients $(50.24 \%)$, housemaid of 6 patients $(1.44 \%)$, private nurse of 6 patients $(1.44 \%)$, home health care (HHC) of 68 patients $(16.27 \%)$ and 128 patients $(30.62 \%)$ not documented who was looking after them.

We found 51 patients $(11.78 \%$ ) were stay in the hospital for long nursing care, 92 patients alive (22.01\%), 326 died (77.99\%). The mean age at death was 77.4. Gender and causes of death are shown in table 4.

Table 4. Causes of death.

\begin{tabular}{llll}
\hline & Frequency & Percent\% & Mean \\
\hline Current status & & & \\
Alive & 92 & 22.01 \\
Male & 50 & & \\
Female & 42 & & \\
Died & 326 & 77.99 \\
Male & 218 & \\
Female & 108 & & 77.4 \\
Age at death & & \\
Cause of death & & \\
Infection & 125 & 38.34 \\
Pneumonia & 85 & 68 \\
Urinary tract infection & 25 & 20 \\
Bed sores & 15 & 12 & \\
Cardiac causes & 57 & 17.48 \\
Heart failure & 34 & 59.65 \\
MI & 14 & 24.56 \\
Other cardiac causes & 9 & 15.79 \\
Malignancy & 19 & 5.83 \\
Stroke & 76 & 23.31 \\
pulmonary embolism & 6 & 1.84 \\
Non specify cause of death (No & 43 & 13.2 \\
autopsy is available) & & \\
\hline
\end{tabular}

\section{Discussion}

78.8 is the mean age of patients and $63.41 \%$ of them diagnosed above age 65years. Older age is strongly associated with dementia and has been reported globally [5, 6]. Dominant gender in this study is male $56.46 \%$. Female sex is a dementia risk factor in many international studies [5]. In the Rotterdam Study the incidence of dementia is higher in women than men; age-specific incidence rates are very similar up to the age of 85years. Whereas in women it continued to rise above age 85 , the difference could be explained by women living longer than men. Framingham study estimates of lifetime risks for dementia $18.4 \%$ and $31.8 \%$ for 75 -year-old men and women, respectively [7].

The prevalence of cardiovascular diseases (CVD) risk factors like hypertension, dyslipidemia and diabetes mellitus (DM) are high in the current study. This may be responsible for the high prevalence of stroke and chronic renal diseases. It is reported that demented patients have a higher number of comorbidities and the two most frequent comorbidities both for men and women are hypertension and DM [8]. Patients with dementia usually have on average 2 to 8 chronic diseases (comorbidities). In our study $27.44 \%$ of patients have more than 3 risk factors comorbidities [9, 10].

The prevalence of DM in general population in Saudi
Arabia is $25.4 \%$ [11]. Another study showed the overall prevalence of DM in Saudis is $23.1 \%$, obesity $31 \%$, hypertension and coronary artery disease $25.1 \%$ in women, $36.5 \%$ in men [12].

Studies finding an association between obesity and incident dementia have usually measured body mass index (BMI) or adiposity in mid rather than late life. Most of these studies found that mid-life obesity increases the risk of dementia later in life. In this study there is no difference in mean BMI on presentation and 7 years later on $[13,14]$. Low BMI in later life is associated with the development of dementia, because weight loss is an early manifestation of the disease rather than a true risk factor [15].

Once Alzheimer's disease (AD) develops patients with higher education or occupational levels appear to experience more rapid cognitive decline as compared with those with less education $[16,17]$. Unfortunately the education level was not documented in $89.1 \%$ of patients.

The prevalence of depression in dementia is reported to be $20-60 \%$ [18]. The relationship between depression and dementia is complex [19]. The prevalence of depression in general Saudi population is $49.9 \%$ [20]. The prevalence in this study is $24.41 \%$ and $30.72 \%$ of them on treatment for depression. In cohort study depressive symptoms have an association with cognitive decline that is independent of the neuropathologic hallmarks of dementia [21]. Vascular and mixed subtypes of dementia have a higher prevalence of depression as compared to AD [22]. Treatment for depression can significantly improve quality of life.

Prevalence of seizure among patients is $18.93 \%$. Epileptic events in dementia are frequent and under recognized. Epileptic seizures after stroke are independent predictors of new-onset dementia. The preexisting vascular pathologies that may predispose to both epileptic seizures and new-onset dementia could be white matter changes, silent infarcts, or microbleeds. This could be due to an underlying preclinical degenerative disorder such as Alzheimer's disease [23]. A seizure in dementia; particularly AD is established in many studies. Mechanisms underlying seizure pathogenesis are unresolved, but recent studies raise the possibility, that seizures are related to the same pathogenetic processes responsible for cognitive decline, Treatment of seizures in dementia remains empirical [24].

HIV prevalence in Saudi Arabia is very low 0.02\% [25]. HIV associated neurocognitive disorder (HAND) encompass a hierarchy of progressively more severe patterns of neurological involvement. It can range from asymptomatic neurocognitive impairment (ANI) to minor neurocognitive disorder (MND) to more severe HIV-associated dementia (HAD) also called AIDS dementia complex (ADC) [26]. The incidence of ADC has dropped by antiretroviral therapy. In this study 8 patients are reported to have HIV and they had dementia when their age $<65$.

Dementia symptoms are cognitive changes and behavioral/ psychological Symptoms of dementia (BPSD). The commonest symptoms among demented patients in this study are memory impairment, confusion and personality changing. 
$27.66 \%$ of patients have more than 3 symptoms on presentation.

The difficulty in caring for patients with $\mathrm{AD}$ is more closely linked to the existence and intensity of the BPSD than the actual cognitive decline. Current treatment for these BPSD is difficult but is generally approached by medications and/or psycho-social support therapies. Several studies have estimated the prevalence of the neuropsychiatric symptoms of dementia to affect $50 \%$ to $80 \%$ of demented patients in the course of the disease [27]. Systematic reviews of the prevalence of BPSD in community-dwelling older people with dementia give widely ranging results, depending on which tools are used and the length of the observation period [28].

Dementia diagnosis is based on structured history, neurological examination and neuropsychological assessment. Neuroimaging will support for but did not change the clinical diagnosis. Laboratory investigations may help to rule out secondary causes of dementia.

The commonest type of dementia among patients is mixed dementia followed by AD. High prevalence of mixed dementia could be related to high prevalence of CVD risk factors like hypertension, dyslipidemia and diabetes mellitus among Saudis. Stroke is reported in $15.03 \%$ of our patients and stroke is well known to doubles the risk of developing dementia [29]. Dementia medications can temporarily improve symptoms and slow the progression of the disease process. $25.88 \%$ of patients have received treatment for dementia, $16.10 \%$ have received cholinesterase inhibitor, $5.22 \%$ have received memantine. Duration of treatment in $10.79 \%$ of patients is $<5$ years and in $8.63 \%$ of patients is $>5$ years.

Feeding can be difficult in demented pateints.30.45\% of patients on gastrostomy tube (GT) feeding. In observational studies, tube feeding has not been shown to prevent aspiration, heal pressure wounds, improve nutritional status, or decrease mortality in persons with advanced dementia. Previous study in Saudi patients reported that $38.1 \%$ of demented patients are on tube feeding and $51 \%$ of them have stroke. Demented patients who have difficulty swallowing or reduced food intake often receive feeding tubes [30]. Demented patients are admitted to hospital two to three times more often than people of the same age without dementia. In the USA, admissions to hospital for people over the age of 85 years with dementia increased from 700000 in 2000 to 1.2 million in 2008. Prevalence of demented patients' admission is $40-43 \%$ in the UK, Italy and Switzerland [31]. The commonest cause of frequent admission among patients is infection (aspiration pneumonia, urinary tract infection and bed sores infection). Infection is the commonest cause of frequent admission as reported in the literature. Frequent admissions and long stay in hospital make the economic cost is high [32]. The caregivers in $50.24 \%$ of patients are family members. Caregivers of demented patients are faced with a number of challenges that can affect their own health and wellbeing which needs further research. $11.78 \%$ of demented patients stay at hospital for long nursing care which make the cost is high because no nursing home in Saudi Arabia.

Dementia is a major risk factor for death in advanced age.
Moderate and severe dementia was associated with an increased mortality risk even after appropriate control of comorbid conditions [33]. Mortality rate among our patients is high. The mean age at death is 77.4. The mean age at death of HIV patients with dementia is 45.5 .

The commonest cause of death is infection followed by cardiovascular causes like stroke and cardiac diseases. No matter what care is offered, the outcome of dementia is likely to be poor. Half of people with moderate dementia admitted with acute illness such as hip fracture or pneumonia will die within 6 months [34]. There is an apparent difference in survival between AD patients with onset of illness before 75 years and those after 75 years: the younger patients have a longer life expectancy. However, there are conflicting data on survival (in years) comparing male and female patients and comparing patients of different ethnicities [35]. Dementia increases the mortality risk at ten years in the NEDICES Study as in other cohort studies. Age and co-morbidity are associated with higher mortality in dementia patients. One third of deaths in persons over 85 years-old could be attributable to dementia [36].

\section{Conclusion}

This study has some limitations. It is a retrospective chart review where some missing data are expected and poor documentation is common. Since this study was performed at tertiary care hospital, generalizability may be limited due to sample size. No autopsy is available. Despite these limitations, up to our knowledge this study is the first data study in Saudi Arabia that highlights the following:

(1) Mixed dementia is the commonest type of dementia in Saudis due to high prevalence of cardiovascular diseases risk factors. Prevent and control these risk factors may help to prevent vascular dementia. (2) High prevalence of depression among demented Saudi patients. It requires early recognition and treatment. (3) Despite lack of evidence that feeding tubes benefit patients with dementia, patients who have difficulty swallowing or reduced food intake often receive feeding tubes, the use of feeding tubes are expected to increase. (4) Demented patients have frequent admissions and long stay in hospital which makes the economic cost is very high. There is an urgent need to have national strategies to open nursing homes in Saudi Arabia. (5) Mortality rate among demented patients is high.

The underlying message of this study is to increase awareness of the public and health system about the impact of dementia in Saudis and the need for prevention strategies, trained physicians and more research.

\section{Conflict of Interest}

The authors declared that there is no conflict of interest

\section{Acknowledgements}

The authors are grateful to Mrs Nada Alhumidan and Mrs 
Nada Bawayan for their effort in data entry and $\mathrm{Mr}$. Abdelmoneim Eldali from Research Centre at KFSH\&RC for his effort in the statistical analysis of our study.

\section{References}

[1] Psychiatric Association: Diagnostic and Statistical Manual of Mental Disorders. 5th edition. Arlington, VA: American Psychiatric Association; 2013.

[2] Qiu C, von SE, et al: Twenty-year changes in dementia occurrence suggest decreasing incidence in central Stockholm, Sweden. Neurology 2013, 80: 1888-1894.

[3] World Health Organization and Alzheimer's disease International (ADI): Dementia: A Public Health Priority. Geneva: World Health Organization; 2012.

[4] Ogunniyi A, Daif AK, et al: Dementia in Saudi Arabia: experience froma university hospital. Acta Neurol Scand 1998: 98: 116120.

[5] Borenstein AR, Copenhaver CI, etal.. Early-life risk factors for Alzheimer disease. Alzheimer Dis Assoc Disord 2006; 20: 63-72.

[6] Alewijn Ott, Incidence and Risk of Dementia: The Rotterdam study. Am. J. Epidemiol. (1998) 147 (6): 574-580.

[7] Seshadri S, Wolf PA, etal. Lifetime risk Of dementia and Alzheimer's disease: estimates fromThe Framingha M Study. Presented at the $48^{\text {th }}$ Annual Meeting Of the American Academy of Neurology, San Francisco, California, March1996.

[8] Beatriz Poblador-Plou. Comorbidity of dementia: a crosssectional study of primary care older patients. BMC Psychiatry 2014, 14: 84.

[9] Schubert CC, Boustani M, et al.: Comorbidity profile of dementia patients in primary care: are they sicker? J Am Geriatr Soc 2006, 54: 104-109.

[10] Sanderson M, Wang J, et al.: Co-morbidity associated with dementia. Am J Alzheimers Dis Other Demen 2002, 17: 7378 .

[11] Al-Rubeaan K, Al-Manaa HA. Epidemiology of abnormal glucose metabolism in a country facing its epidemic: SAUDIDM study. J Diabetes. 2014 Sep 30.

[12] Al-Daghri et al. Diabetes mellitus type 2 and other chronic non-communicable diseases in the central region, Saudi Arabia (Riyadh cohort 2): a decade of an epidemic. BMC Medicine 2011, 9: 76.

[13] Cournot M, Marquié JC, et al. Relation between body mass index and cognitive function in healthy middle-aged men and women. Neurology 2006; 67: 1208.

[14] Albanese E, Davis B, et al. Overweight and Obesity in Midlife and Brain Structure and Dementia 26 Years Later: The AGESReykjavik Study. Am J Epidemiol 2015; 181: 672.

[15] Burns JM, Johnson DK, et al. Reduced lean mass in early Alzheimer disease and its association with brain atrophy. Arch Neurol 2010; 67: 428.

[16] Wilson RS, Li Y, et al. Education and the course of cognitive decline in Alzheimer disease. Neurology 2004; 63: 1198.

[17] Hall CB, Derby C, et al. Education delays accelerated decline on a memory test in persons who develop dementia. Neurology 2007; 69: 1657.

[18] Tsuno N, Homma A. What is the association between depression and Alzheimer's disease? Expert Rev Neurother. 2009; 9: 1667-76.

[19] Rubin EH, Veiel LL, et al. Clinically significant depressive symptoms and very mild to mild dementia of the Alzheimer type. Int J Geriatr Psychiatry. 2001; 16: 694-701.

[20] Al-Qadhi W, Ur Rahman S. et al. Adult depression screening in Saudi primary care: prevalence, instrument and cost. BMC Psychiatry. 2014 Jul 3; 14: 190.

[21] Robert S. Wilson, Ana W, et al. Bennett. Clinical-pathologic study of depressive symptoms and cognitive decline in old age. Neurology, August 19, 2014, 83: 702-709.

[22] Castilla-Puentes RC, Habeych ME. Subtypes of depression among patients with Alzheimer's disease and other dementias. Alzheimer's Dement. 2010; 6: 63-9.

[23] Campana Chiara, Assenza Giovanni, et al, Nonconvulsive Seizures and Dementia: A Case Report. International Journal of Alzheimer's Disease, Volume 2011 (2011), Article ID 690305, 4 pages.

[24] AJ Larner. Epileptic seizures in neurodegenerative dementia syndromes. JOURNAL OF NEUROLOGY AND NEUROSCIENCE (2010), Vol. 1, No. 1:3.

[25] AF Alothman, K Mohajer, Prevalence of HIV-infection in Saudi Arabia, BMC Proceedings20115 (Suppl 6): P252.

[26] Nomenclature and research case definitions for neurologic manifestations of human immunodeficiency virus-type 1 (HIV-1) infection. Report of a Working Group of the American Academy of Neurology AIDS Task Force. Neurology. 1991 Jun. 41 (6): 778-85.

[27] Constantine G. Lyketsos, Oscar Lopez, Prevalence of Neuropsychiatric Symptoms in Dementia and Mild Cognitive Impairment Results From the Cardiovascular Health Study. JAMA. 2002; 288 (12): 1475-1483.

[28] Van der Linde RM et al Systematic reviews on behavioural and psychological symptoms in the older or demented population. Alzheimers Res Ther 2012; 4: 28.

[29] Gorelick PB, Scuteri A, et al; Vascular contributions to cognitive impairment and dementia: a statement for healthcare professionals from the American heart association/American stroke association. Stroke. 2011 Sep; 42 (9): 2672-713.

[30] Muneerah Albugami, Yasmin Al Twaijri, et al. Impact of Tube Feeding on Aspiration Pneumonia at Tertiary Care Hospital. American Journal of internal Medicine. 2015 2015; 3 (3): 95102.

[31] Elizabeth L. Sampson, et al Behavioural and psychiatric symptoms in people with dementia admitted to the acute hospital: prospective cohort study. The British Journal of Psychiatry Sep 2014, 205 (3) 189-196.

[32] Elizabeth L. Sampson, Nicola White, et al. Behavioural and psychiatric symptoms in people with dementia admitted to the acute hospital: prospective cohort study. The British Journal of Psychiatry Sep 2014, 205 (3) 189-196. 
[33] Llinàs-Regla J, López-Pousa $\mathrm{S}$, et al. Mortality after a diagnosis of dementia in a population aged 75 and over in Spain. Neuroepidemiology. 2008; 31 (2): 80-8.

[34] Morrison RS, Siu AL (2000) Survival in end-stage dementia following acute illness. JAMA 284: 47-52.
[35] Kua EH, Ho E, Tan HH, et al; The natural history of dementia. Psychogeriatrics. 2014 Sep; 14 (3): 196-201.

[36] Villarejo A, Benito-León J. et al Dementia-associated mortality at thirteen years in the NEDICES Cohort Study. J Alzheimers Dis. 2011; 26 (3): 543-51. 